\title{
Survey on Depression among Dental Professionals in Pakistan
}

\author{
Hashmat Gull ${ }^{1 *}$, Abida Saleem², Ayesha Aslam ${ }^{3}$, Ujala Liaqat ${ }^{4}$, Abdul Samad Khan ${ }^{5}$
}

\section{ABSTRACT}

Objective: To assess association of depression among Pakistani dentists with demographic variables and correlate patient health questionnaire (PHQ-9) depression severity measure (DSM) variables.

Study Design: Cross sectional study.

Place and Duration of Study: The study was carried out at Department of Dental Materials, Army Medical College, Rawalpindi from March 2018 to October 2018.

Materials and Methods: Minimum sample size of 350 was ascertained at $95 \%$ confidence level via Raosoft sample size calculator. Targeted population included 378 Pakistani dentists. Consent from Institutional Review Board and study participants was taken. SPSS version 21 was utilized to analyze and interpret the collected data. Percentages were used to present categorical variables. Chi-square test was used to compare association of DSM with demographic variables. Pearson Correlations between all PHQ-9 variables and DSM was also established. $P<0.05$ was taken significant.

Results: Majority of study participants were female dentists (63.2\%) from Punjab (63.2\%), 27-31 years old (33.3\%), married (56.6\%) and only BDS qualified (66.9\%). Majority were M.Phil./FCPS residents (31\%) with $\leq 5$ years' work experience (64\%), working $\geq 48$ hours/week (42.3\%). Statistically significant association of DSM was observed with province, age, marital status, designation and experience. Statistically significant correlations were observed between all PHQ-9 variables and DSM.

Conclusion: Dentistry is dominated by young Pakistani females, majority of whom are pursuing higher education and exhibit moderate depression. Depression is more pronounced among young, single, fresh graduates with $\leq 5$ years' work experience.

\section{Key Words: Depression, Dental professionals, Female Dentists, Suicide}

How to cite this: Gul H, Saleem A, Aslam A, Liaqat U, Khan AS. Survey on Depression among Dental Professionals in Pakistan. Life and Science. 2022; 3(1): 13-19. doi: http://doi.org/10.37185/LnS.1.1.206

This is an Open Access article distributed under the terms of the Creative Commons Attribution License (http://creativecommons.org/licenses/by/4.0), which permits unrestricted use, distribution, and reproduction in any medium, provided the original work is properly cited.

\section{Introduction}

Dentistry is a stressful profession and is associated

${ }^{1}$ Department of Dental Materials/ Prosthodontics ${ }^{3}$
Army Medical College, Rawalpindi
${ }^{2}$ Department of Dental Materials
Shifa College of Dentistry, Islamabad
${ }^{4}$ Department of Leadership and Management Studies
National Defense University, Islamabad
${ }^{5}$ Department of Restorative Dental Sciences
College of Dentistry
Imam Abdulrahman Bin Faisal University
Saudi Arabia
Correspondence................................................
Dr. Hashmat Gul
Department of Dental Materials
Army Medical College, Rawalpindi
E-mail: dr.hashmatgul@yahoo.com
Funding Source..................................................
Received: May 07, 2021; Revised: Jul 08,2021
Accepted: Oct 16, 2021

${ }^{1}$ Department of Dental Materials/ Prosthodontics ${ }^{3}$

Army Medical College, Rawalpindi

${ }^{2}$ Department of Dental Materials

Shifa College of Dentistry, Islamabad

${ }^{4}$ Department of Leadership and Management Studies

National Defense University, Islamabad

${ }^{5}$ Department of Restorative Dental Sciences

College of Dentistry

Imam Abdulrahman Bin Faisal University

Saudi Arabia

Correspondence:

Dr. Hashmat Gul

Department of Dental Materials

Army Medical College, Rawalpindi

E-mail:dr.hashmatgul@yahoo.com

Funding Source: NIL; Conflict of Interest: NIL

Accepted: Oct 16, 2021 with high prevalence of distress and mental health issues than the general population..$^{1-3}$ In 2018, Rothermund et al. reported depression as the second most common disability globally. ${ }^{4}$ In 2014 , Steel et al. presented a systematic review and metaanalysis in 188 countries between 1990 - 2003, and concluded that approximately $15-20 \%$ of working population suffer from a mental disorder at any one time. ${ }^{5}$ Depression and anxiety levels are important indicators of psychological health. ${ }^{6}$ Accurate estimation of prevalence rates is hard; due to extensive difference in the procedures used to assess depression in research. ${ }^{3}$ Long working hours, extensive workload, huge responsibilities, and a distress of committing blunders are features of dental practice which seem to accord straight to work stress and fatigue. ${ }^{7}$ Certain personalities and 
intellectual qualities shared by health care practitioners may place them at high risk of acquiring psychological illnesses. ${ }^{8}$ Traits such as carefulness and conscientiousness, are evident in healthcare professionals which are linked to perfectionism, rigor, over-commitment, self-critique, and inability to relax. ${ }^{9}$ These elements may hinder the ability of healthcare professionals to tackle the "stressors" accompanying the healthcare career and may be a source of specific susceptibility of healthcare professionals given the arduous academic demands of the degree. ${ }^{10}$ Prescription anxiolytic drugs like benzodiazepines are used more frequently among medical professionals as compared to general population, apparently owing to the relative ease of access. ${ }^{11}$

In spite of their knowledge and awareness about depression and suicide, healthcare professionals are often hesitant to pursue professional help for their personal psychological health problems. ${ }^{12,13}$ Common cited barriers include effect on colleagues, on patients and concerns for carrier impact. It is believed that mental health issues lead to reduced proficiency and feebleness and make healthcare professionals less likely to be employed. These beliefs are mainly problematic because not only they pose stigma but may also increase the likelihood of depression and suicide. ${ }^{14}$ This raises questions about the competence of medical professionals to support others, including peers and patients. Literature reports that dental students who screened positive for depression, less than $16 \%$ sought professional psychiatric help. ${ }^{15}$ Previous studies. ${ }^{16-18}$ conducted in Pakistan were exclusively targeted to certain study group and associated shortcomings were small sample size, limitation to one or 2-3 dental schools, using different well-being or anxiety assessing tools, and focusing mainly on job stressors. Therefore, there is a need to gather information from all over the country and target larger population on this intricate topic.

The research objectives of this cross-sectional study were two-fold. Firstly, it intended to evaluate the association of depression on the basis of patient health questionnaire (PHQ) score with the demographic variables i.e. age, gender, marital status, degree, work experience, current position, and daily working time. Secondly, to evaluate the correlations between all the variables assessing depression on basis of PHQ-score.

\section{Materials and Methods}

The Current study was carried out in two phases, a pilot study followed by the main study. Pilot study comprised of 170 respondents from four teaching dental colleges of Rawalpindi and Islamabad. After assurance of sensitivity of the depression assessing tool via pilot study, e-questionnaire was developed and distributed among dentists serving in Pakistan. A cross sectional study was carried out through patient health questionnaire (PHQ-9), which has comparable sensitivity and specificity, and consists of the actual 9 criteria upon which diagnosis of depression severity measure (DSM) is carried out. The PHQ 9 has potential of being dual purpose tool that can establish depressive disorder diagnosis as well as can grade depressive symptoms severity too. $^{19}$

The PHQ 9 was completed by 378 Pakistani dental professionals. The study was accomplished in Pakistan from March 2018 to October 2018. Nonprobability convenience sampling technique was employed. Raosoft sample size calculator was utilized to ascertain the sample size of 350 with the confidence level of $95 \%$. The target population in our research comprised a total of 378 qualified Pakistani dental practitioners serving in various cities of Pakistan.

Respective authorities were approached for approval to conduct the study smoothly. Besides, the participants were intimated about the outcomes of the study with appropriate instructions to fill the questionnaire. This study utilized the questionnaire adapted from "Primary Care Evaluation of Mental Disorders Patient Health Questionnaire" (PRIME-MD PHQ) to collect data anonymously. Initial seven questions were designed to collect demographic details. Ten questions from PRIME-MD PHQ intended to assess the level of depression among the participants which were measured on a scale ranging from 0 to 3.

SPSS version 21 (SPSS software, IBM, USA) was utilized to analyze and interpret the collected data. For categorical variables percentages and frequencies were calculated. Association between level of depression on basis of PHQ-Score with the demographic variables was compared and analyzed 
using Chi square Test, where $p \leq 0.05$ was taken as significant.

\section{Results}

In pilot majority of study participants were 22-26 years old (41\%), females (73.4\%), married (54.9\%), BDS qualified (79.2\%), with $0-5$ years' work experience $(75.7 \%)$ and working as demonstrators (28.3\%) for $42-47$ hours/week (59\%). Statistically significant association of DSM was observed with age ( $p=0.018)$, work experience $(p=0.024)$ and designation ( $p=0.000$ ) only. A statistically significant Pearson Correlations was observed between all the PHQ-9 variables including DSM except between suicidal thoughts and little interest in doing things ( $p$ $=0.351)$ and feeling tired $(p=0.021)$.

The main study comprised 378 dentists from all parts of Pakistan (including participants of pilot study), whereby majority were from province Punjab (63.2\%) and least were from Baluchistan (1\%). Majority of the study participants were 27-31 years old (33.3\%), females (63.2\%), married (56.6\%), Bachelors in Dental Surgery (BDS) qualified (66.9\%). Majority of the study participants were working as M.Phil/MDS/FCPS residents (31\%) with $\leq 5$ years' work experience $(64 \%)$ and exhibited $\geq 48$ working hours/week (42.3\%). The detailed account of the demographic details of the study participants is given in Table 1.

\begin{tabular}{llcc}
\hline \multicolumn{3}{l}{$\begin{array}{l}\text { Table 1: Demographic details of the study participants in } \\
\text { terms of frequency and percent }\end{array}$} \\
\hline Variable & Response & $\begin{array}{l}\text { Frequency } \\
\text { ( } \mathbf{n = 3 7 8 )}\end{array}$ & $\begin{array}{l}\text { Percent } \\
\text { (\%) }\end{array}$ \\
Province & Federal & 35 & 9.3 \\
& Capital/Islamabad & & \\
& Punjab & 239 & 63.2 \\
& KPK & 66 & 17.5 \\
& Sindh & 34 & 9 \\
Age & Balochistan & 4 & 1 \\
& 22-26 Years & 118 & 31.2 \\
& 27-31 Years & 126 & 33.3 \\
& 32-36 Years & 82 & 21.7 \\
Gender & $>36$ Years & 52 & 13.8 \\
& Male & 139 & 36.8 \\
Marital & Female & 239 & 63.2 \\
Status & Single & 151 & 39.9 \\
& Married & 214 & 56.6 \\
Qualification & Divorced/Widow & 13 & 3.4 \\
& BDS & 253 & 66.9 \\
& MS/M.Phil. & 53 & 14 \\
& PhD / FCPS & 72 & 19 \\
\hline
\end{tabular}

\begin{tabular}{llcc}
\hline Work & 0-5 Years & 242 & 64 \\
\cline { 2 - 4 } Experience & $6-10$ Years & 82 & 21.7 \\
\cline { 2 - 4 } & $11-15$ Years & 27 & 7.1 \\
\cline { 2 - 4 } & $>15$ Years & 27 & 7.1 \\
\hline Current & House Officer & 70 & 18.5 \\
\cline { 2 - 4 } Designation & $\begin{array}{l}\text { Demonstrator/ } \\
\text { Lecturer/ Clinician }\end{array}$ & 80 & 21.2 \\
\cline { 2 - 4 } & $\begin{array}{l}\text { M.Phil. /FCPS } \\
\text { Resident }\end{array}$ & 117 & 31 \\
\cline { 2 - 4 } & $\begin{array}{l}\text { Senior } \\
\text { Lecturer/Registrars }\end{array}$ & 33 & 8.7 \\
\cline { 2 - 4 } & Professors & 78 & 20.6 \\
\hline Working & $36-41$ Hours & 78 & 20.6 \\
\cline { 2 - 4 } time/week & 42-47 Hours & 140 & 37 \\
\cline { 2 - 4 } & $\geq 48$ Hours & 160 & 42.3 \\
\hline
\end{tabular}

A statistically significant association of DSM on basis of PHQ-score was observed with age $(p=0.000)$, marital status $(p=0.017)$, degree $(p=0.014)$, work experience $(p=0.000)$, designation $(p=0.001)$, and working hours/week ( $p=0.039)$ (Table 2)

\begin{tabular}{|c|c|c|c|c|c|c|}
\hline \multirow[t]{2}{*}{ Variables } & \multicolumn{4}{|c|}{ Level of Depression on Basis of PHQ-Score } & \multirow[t]{2}{*}{ Total } & \multirow{2}{*}{$\begin{array}{c}p \\
\text { Value }\end{array}$} \\
\hline & $\begin{array}{c}\leq 5 \\
\text { Lower } \\
\text { Limits of } \\
\text { Mild } \\
\text { Depression }\end{array}$ & $\begin{array}{c}\leq 10 \\
\text { Lower } \\
\text { Limits of } \\
\text { Moderate } \\
\text { Depression }\end{array}$ & $\begin{array}{c}\leq 15 \\
\text { Lower } \\
\text { Limits of } \\
\text { Moderately } \\
\text { Severe } \\
\text { Depression }\end{array}$ & $\begin{array}{c}\leq 20 \\
\text { Lower } \\
\text { Limits of } \\
\text { Severe } \\
\text { Depression }\end{array}$ & & \\
\hline \multicolumn{7}{|l|}{ Residence/Province } \\
\hline Islamabad & 10 & 10 & 11 & 4 & 35 & \\
\hline Punjab & 91 & 92 & 36 & 20 & 239 & \\
\hline KPK & 39 & 14 & 7 & 6 & 66 & .007 \\
\hline Baluchistan & 2 & 0 & 2 & 0 & 4 & \\
\hline Sindh & 8 & 14 & 8 & 4 & 34 & \\
\hline Total & 150 & 130 & 64 & 34 & 378 & \\
\hline \multicolumn{7}{|l|}{ Age } \\
\hline $22-26$ & 29 & 57 & 20 & 12 & 118 & \\
\hline $27-31$ & 47 & 35 & 31 & 13 & 126 & .000 \\
\hline $32-36$ & 44 & 26 & 7 & 5 & 82 & \\
\hline$>36$ & 30 & 12 & 6 & 4 & 55 & \\
\hline Total & 150 & 130 & 64 & 34 & 378 & \\
\hline \multicolumn{7}{|l|}{ Marital Status } \\
\hline Divorced & 7 & 3 & 1 & 2 & 13 & \\
\hline Single & 47 & 62 & 23 & 19 & 151 & .025 \\
\hline Married & 96 & 65 & 40 & 13 & 214 & \\
\hline Total & 150 & 130 & 64 & 34 & 378 & \\
\hline \multicolumn{7}{|l|}{ Degree } \\
\hline BDS only & 83 & 96 & 46 & 28 & 253 & \\
\hline MS/M.Phil. /MCPS & 27 & 17 & 6 & 3 & 53 & \\
\hline $\mathrm{PhD} / \mathrm{FCPS} / \mathrm{MD}$ & 40 & 17 & 12 & 3 & 72 & .007 \\
\hline Total & 150 & 130 & 64 & 34 & 378 & \\
\hline \multicolumn{7}{|l|}{ Work Experience } \\
\hline $00-05$ Years & 74 & 98 & 46 & 24 & 242 & \\
\hline 06-10 Years & 39 & 21 & 14 & 8 & 82 & \\
\hline 11-15 Years & 17 & 7 & 2 & 1 & 27 & .000 \\
\hline$>15$ Years & 20 & 4 & 2 & 1 & 27 & \\
\hline Total & 150 & 130 & 64 & 34 & 378 & \\
\hline \multicolumn{7}{|l|}{ Designation } \\
\hline House Officers & 19 & 32 & 8 & 11 & 70 & \\
\hline Demonstrators/Lecturers & 32 & 35 & 10 & 3 & 80 & \\
\hline M.Phil./FCPS Residents & 42 & 31 & 29 & 15 & 117 & .001 \\
\hline Senior Lecturers & 13 & 11 & 6 & 3 & 33 & \\
\hline Professors & 44 & 21 & 11 & 2 & 78 & \\
\hline Total & 150 & 130 & 64 & 34 & 378 & \\
\hline
\end{tabular}


Frequencies of PRIME-MD PHQ variables in the survey covering Pakistani Dentists along with their responses are given in Figure 1.

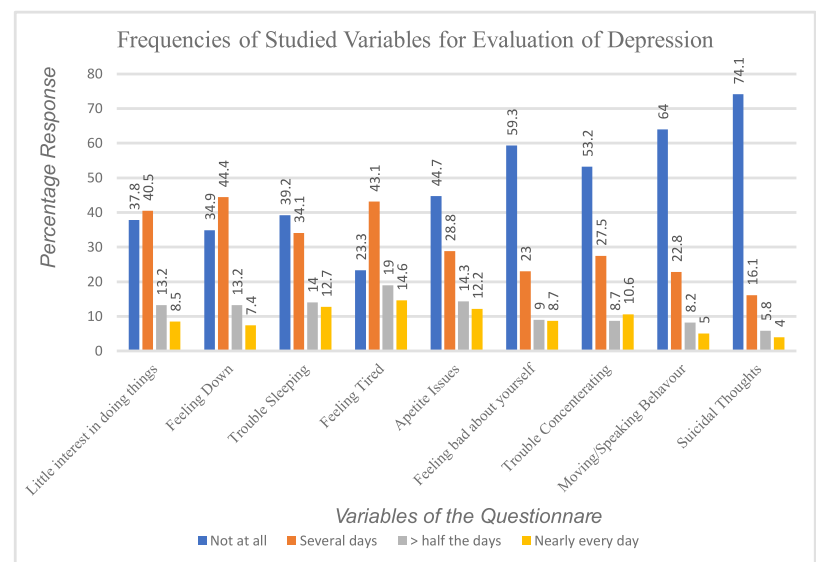

Fig 1: Number and Frequencies of PRIME-MD PHQ Variables in the Survey Performed among Pakistani Dentists ( $\mathrm{N}=\mathbf{3 7 8}$ )
A statistically significant Pearson Correlation as shown in Table 3 was observed between all PHQ-9 variables of DSM including the PHQ-score $(p=\leq$ 0.001).

\section{Discussion}

Depression is one of the most predominant yet curable psychological disorder. Depression is experienced by a wide range of health care workers as well. ${ }^{4}$ In primary care, a number of case finding instruments are present for depression detection, which range from 2-28 items in length which can be scored as continuous measure of the severity of depression. These scores display correlation and show no evidence of any superiority of one measure to another. ${ }^{19}$ PHQ-9 is one of the instrument used for producing criteria-based diagnosis and has gained popularity since the last two decades ${ }^{19,20}$ and was

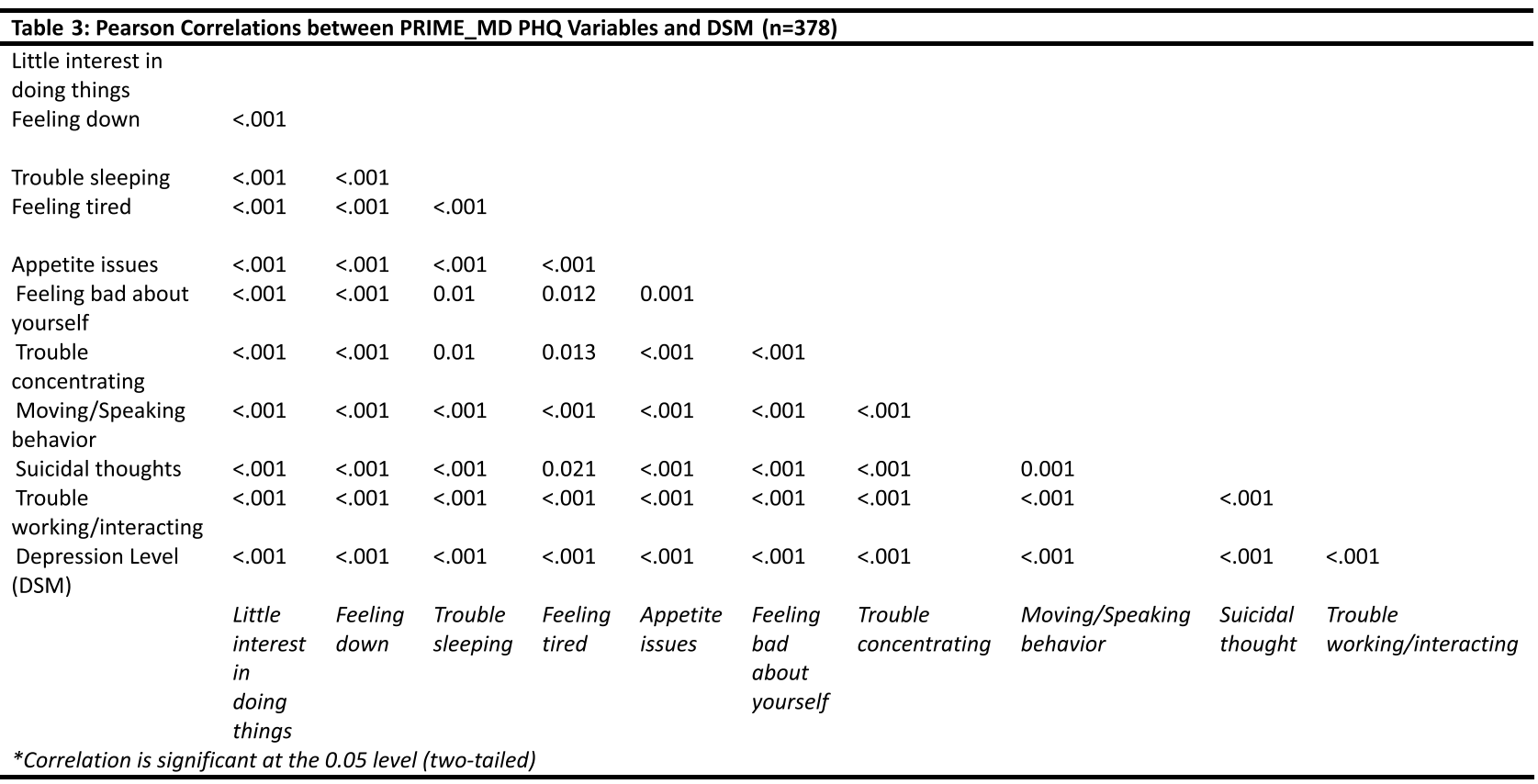

used in this study too.

Better living standards, career development opportunities and job security play crucial role in a person's mental satisfaction level. All these aspects vary in different regions of Pakistan, so do the mental status of dentists serving in different regions of Pakistan. Statistically significant association of depression level with residence of study participants was observed ( $p=0.007$ ) (Table 2). Moderate depression was common in Punjab, Sindh, and Federal Capital whereas dentist's majority in KPK displayed mild depression. Severe depression was least common among Pakistani dentists. This indicates greater job satisfaction level at KPK followed by federal capital then Punjab, Sindh and least in Baluchistan.

Female dentists dominated the study (64\%) showing greater popularity of dentistry profession among Pakistani women. Previous studies have reported that young female medical professionals are at greater risk of developing depression and two fold higher suicide tendencies in severe cases as compared to their male colleagues and general population. ${ }^{21-23}$ Pregnancy can also be an additional 
source of stress. ${ }^{24}$ In contrast, no association of depression with gender was observed in this study, with majority reporting no suicidal thoughts (72.6\%). This might be attributed to the Muslim ethnic majority population in our study, where religiously and culturally, suicide is deemed 'forbidden'. Majority of the study participants seemed content with their lives and denied having any depression symptoms for not even a single day during the past two weeks.

Greater majority of dentists in this study were married $(57.7 \%)$ and exhibited lower limits of mild $(44.8 \%)$ and moderate depression (41.1\%), which is in contrast with previous study ${ }^{25}$, where married people showed higher level of depression as compared to unmarried practitioner due to increased level of social and financial liabilities. Majority of the unmarried dentists (41.1\%) in this study exhibited lower limits of moderate depression. This might be due to increased trends of isolation among the millennial generation, and increased societal pressures in terms of developing a career and family.

Majority (75.7\%) of the study participants had $0-5$ years' work experience and were of about 27-31 years of age (32\%). Statistically significant association of depression level with age $(p=<0.001)$ was reported, which indicated that depression was more prevalent among young dentists i.e. 22-31 years of age and an inverse proportionality of level of depression with age group was observed which is in accordance with the study conducted by Song et al. in 2017..$^{22}$ Greater anxiety among young dentists could be attributed to the tough competition and desire to excel in their careers.

A statistically significant association between depression level and designation was observed $(p=$ 0.001 ) in this study as well. Whereby, moderately severe to severe depression among junior dentists especially residents, house officers, and senior lecturers, indicated that depression is more prevalent among junior doctors. Junior dentists face greater uncertainty and demands of their budding career and family life. On the other hand, majority of consultants with well settled careers and family life showed lower limits of mild depression (56.4\%).

In this study, majority were residents of clinical and basic dental sciences $(27.1 \%)$ indicating greater inclination of dentists towards pursuing higher education. Resident physicians tend to be at an advanced risk of acquiring stress than the senior physicians because of absence of interactive and communication skills; medical grasp and practice. Long working hours and working conditions create a key cause of chronic stress, which may lead to mental health complications, including depression and suicide in extreme cases. ${ }^{3,7}$ In this study, majority of residents (38.3\%) reported moderately severe depression and $14.9 \%$ reported severe depression, which is in accordance to a recent study by Ogawa et al. ${ }^{10}$ in which depression reported among residents ranged from $7-35 \%$. Higher level of depression among residents in this study could be attributed to the fact that they are over-burdened not only physically but mentally as well due to their tough training schedule, stress of passing examinations along with meeting their daily life commitments. In 2018, Loas et al. ${ }^{26}$ found significant relationship among depression and suicidal tendencies among health professionals and medical students, which is in accordance with this study findings as a similar statistically significant correlation was observed between depression expressed by PHQ-score and all the stress symptoms $(p \leq 0.001)$.

\section{Conclusion}

This study showed the greater popularity of dentistry among young Pakistani females with majority exhibiting moderate depression. Majority of the study participants were undergoing postgraduation training, showing the urge of young Pakistani dentists to excel in their careers by pursuing higher education. Among demographic variables, statistically significant association of depression level was observed with age, marital status, degree, designation, and work experience. No statistically significant association was observed with gender and weekly working hours. An inverse relation of level of depression with age group/designation was observed. It is concluded that the statistically significant correlations of depression levels with all depression symptoms was observed proving PHQ-9 as an efficient DSM tool.

\section{Future Recommendations}

It is important to recognize factors which predispose to depression and stress in order to aid diagnosis and treatment. The identification of modifiable risk 
factors such as the working environment or training requirements can help to develop effective treatment strategies and prevention for future. In fact, a multi-level approach that include psychotherapy, target stigma and provide evidencebased treatment and support where needed.
Doctor's health care programs and services should be offered to cater the specialized need of doctors aiming to help them prior to the development of severe depression and anxiety disorders. These approaches should utilize both face to face and online options.

\section{Appendix-A}

Questionnaire: Evaluation of Depression among Medical Professionals

This study is conducted solely for research purpose, all the details regarding the participants will be kept confidential. Attempt all/ relevant questions please.

\begin{tabular}{|c|c|c|c|c|}
\hline Date: & \multicolumn{4}{|c|}{ Age: _ } \\
\hline Marital st & \multicolumn{4}{|c|}{ Marital status: } \\
\hline Degree/s: & \multicolumn{4}{|c|}{ Years of Experience: } \\
\hline Current/Post/Position: & \multicolumn{4}{|c|}{ Working hours: } \\
\hline $\begin{array}{l}\text { Over the last } 2 \text { weeks, how often have you been } \\
\text { bothered by any of the following problems? }\end{array}$ & $\begin{array}{l}\text { Not at } \\
\text { all }\end{array}$ & $\begin{array}{l}\text { Several } \\
\text { days }\end{array}$ & $\begin{array}{l}\text { More than } \\
\text { half the } \\
\text { days }\end{array}$ & $\begin{array}{l}\text { Nearly } \\
\text { every day }\end{array}$ \\
\hline 1. Little interest or pleasure in doing things & 0 & 1 & 2 & 3 \\
\hline 2. Feeling down, depressed, or hopeless & 0 & 1 & 2 & 3 \\
\hline 3. Trouble falling or staying asleep, or sleeping too much & 0 & 1 & 2 & 3 \\
\hline 4. Feeling tired or having little energy & 0 & 1 & 2 & 3 \\
\hline 5. Poor appetite or overeating & 0 & 1 & 2 & 3 \\
\hline $\begin{array}{l}\text { 6. Feeling bad about yourself-or that you are a failure or } \\
\text { have let yourself or your family down }\end{array}$ & 0 & 1 & 2 & 3 \\
\hline $\begin{array}{l}\text { 7. Trouble concentrating on things, such as reading the } \\
\text { newspaper or watching television }\end{array}$ & 0 & 1 & 2 & 3 \\
\hline $\begin{array}{l}\text { 8. Moving or speaking so slowly that other people could } \\
\text { have noticed? Or the opposite-being so fidgety or } \\
\text { restless that you have been moving around a lot more } \\
\text { than usual }\end{array}$ & 0 & 1 & 2 & 3 \\
\hline $\begin{array}{l}\text { 9. Thoughts that you would be better off dead or of } \\
\text { hurting yourself in some way }\end{array}$ & 0 & 1 & 2 & 3 \\
\hline
\end{tabular}

(For office coding: Total Score $=$ $+$

If you checked off any problems, how difficult have these problems made it for you to do your work, take care of things at home, or get along with other people?

\begin{tabular}{|c|c|c|c|}
\hline Not difficult at all & Somewhat difficult & Very difficult & Extremely difficult \\
\hline $\begin{array}{l}\text { ERENCES } \\
\text { Milner AJ, Maheen } \\
\text { health professionals } \\
\text { Australia, 2001-2012 } \\
2016 ; 205: 260-5 \text {. }\end{array}$ & $\begin{array}{l}\text { ark MM, Spittal MJ. Suic } \\
\text { rospective mortality st } \\
\text { Medical Journal of Aus }\end{array}$ & \multicolumn{2}{|c|}{$\begin{array}{l}\text { 2. Mata DA, Ramos MA, Bansal N, Khan R, Guille C, Di } \\
\text { Angelantonio } E \text {, et al. Prevalence of depression and } \\
\text { depressive symptoms among resident physicians: a } \\
\text { systematic review and meta-analysis. The Journal of the } \\
\text { American Medical Association. 2015;314:2373-83. }\end{array}$} \\
\hline
\end{tabular}


3. Bailey E, Robinson J, McGorry P. Depression and suicide among medical practitioners in Australia. Internal Medicine Journal. 2018; 48: 254-8.

4. Rothermund E, Michaelis M, Jarczok MN, Balint EM, Lange $\mathrm{R}$, Zipfel S, et al. Prevention of common mental disorders in employees. Perspectives on collaboration from three health care professions. International Journal of Environmental Research and Public Health. 2018; 15: 27890.

5. Steel Z, Marnane C, Iranpour C, Chey T, Jackson JW, Patel V, et al. The global prevalence of common mental disorders: a systematic review and meta-analysis 1980-2013. International Journal of Epidemiology. 2014; 43: 476-93.

6. Inam SB. Anxiety and depression among students of a medical college in Saudi Arabia. International Journal of Health Sciences. 2007; 1: 295.

7. Dyrbye LN, West CP, Satele D, Boone S, Tan L, Sloan J, et al. Burnout among US medical students, residents, and early career physicians relative to the general US population. Academic Medicine. 2014; 89: 443-51.

8. Mata DA, Ramos MA, Bansal N, Khan R, Guille C, Di Angelantonio $E$, et al. Prevalence of Depression and Depressive Symptoms Among Resident Physicians: A Systematic Review and Meta-analysis. Survey of Anesthesiology. 2016; 60: 146-83.

9. Kõlves K, De Leo D. Suicide in medical doctors and nurses: An analysis of the Queensland Suicide Register. The Journal of Nervous and Mental Disease. 2013; 201: 987-90.

10. Ogawa R, Seo E, Maeno T, Ito M, Sanuki M, Maeno T. The relationship between long working hours and depression among first-year residents in Japan. BMC medical education. 2018; 18: 1-8.

11. Elliot L, Tan J, Norris S. The mental health of doctors: a systematic literature review: Beyond Blue; 2010.

12. Yap $\mathrm{MBH}$, Reavley N, Jorm AF. Where would young people seek help for mental disorders and what stops them? Findings from an Australian national survey. Journal of Affective Disorders. 2013; 147: 255-61.

13. Adams EF, Lee AJ, Pritchard CW, White RJ. What stops us from healing the healers: a survey of help-seeking behaviour, stigmatisation and depression within the medical profession. International Journal of Social Psychiatry. 2010; 56:359-70.

14. Swannell C. A perfect storm. The Medical Journal of Australia. 2015; 202: C1.

15. Schwenk TL, Gorenflo DW, Leja LM. A survey on the impact of being depressed on the professional status and mental health care of physicians. The Journal of clinical psychiatry. 2008; 69: 617-20.

16. Khan A, Alvi H, Qadeer S, Khan A, Khan KI, Khan NS. The prevalence of stress and associated factors in dentists working at Islamic International Dental College Hospital, Islamabad. Pakistan Oral and Dental Journal. 2010; 30: 5215.

17. Abdullah S, Saeed T. Comparison of role stressors, job satisfaction and turnover intensions of dentists working in public and private sectors. Pakistan Oral \& Dental Journal. 2013; 33: 412-7.

18. Azad AA, Qurrat-Ul-Ain S, Nisar N, Ashfaq M, MUNIR A, Ahmed $A$, et al. Prevalence of stress and burnout among dentists of Rawalpindi and Islamabad. Pakistan Oral \& Dental Journal. 2013; 33: 407-11.

19. Kroenke K, Spitzer R, Williams J. The PHQ-9: validity of a brief depression severity measure. [Research Support. NonUS Gov't. 2001.

20. Manea L, Gilbody S, McMillan D. Optimal cut-off score for diagnosing depression with the Patient Health Questionnaire (PHQ-9): a meta-analysis. Cmaj. 2012; 184: E191-6.

21. Aboalshamat K, Hou XY, Strodl E. Psychological well-being status among medical and dental students in Makkah, Saudi Arabia: A cross-sectional study. Medical Teacher. 2015; 37: S75-S81.

22. Song KW, Choi WS, Jee HJ, Yuh CS, Kim YK, Kim L, et al. Correlation of occupational stress with depression, anxiety, and sleep in Korean dentists: cross-sectional study. BMC Psychiatry. 2017; 17: 398-408.

23. Ballenger J. A Survey on the Impact of Being Depressed on the Professional Status and Mental Health Care of Physicians. Year Book of Psychiatry \& Applied Mental Health. 2009; 2009: 222-3.

24. Riley GJ. Understanding the stresses and strains of being a doctor. Medical Journal of Australia. 2004; 181: 350-3.

25. Gorter RC, Freeman R. Burnout and engagement in relation with job demands and resources among dental staff in Northern Ireland. Community Dentistry and Oral Epidemiology. 2011; 39: 87-95.

26. Loas G, Lefebvre G, Rotsaert M, Englert Y. Relationships between anhedonia, suicidal ideation and suicide attempts in a large sample of physicians. PloS one. 2018; 13: e0193619. 